\title{
Qualitative phytochemical exploration guided in vitro antibacterial activity studies on crude stem bark extract of stereospermum kunthainum (Bignoniaceae)
}

Lamessa Bekele Ameja

Bahir Dar University

Misganew Tegegne Ayana

Bahir Dar University

Zelalem Bitew Derese

Bahir Dar University

Yinebeb Tariku

Jimma University

Fantahun Aklog Yihun

Bahir Dar University

Mulugeta Tesemma Kassa ( $\square$ Mullumbe2001@yahoo.com )

Bahir Dar University

Legesse Adane Bahiru

Hawassa University

\section{Research Article}

Keywords: S.kuntainum, stem bark, crude extract, phytochemical exploration, antibiotic resistant, in vitro antibacterial activity.

Posted Date: January 31st, 2022

DOI: https://doi.org/10.21203/rs.3.rs-1294105/v1

License: (9) This work is licensed under a Creative Commons Attribution 4.0 International License. Read Full License 


\section{Abstract}

Background: Stereospermum kunthianum plant is known by local name Botoro, in Ethiopia and widely used by traditional medical practitioners for the treatment of venereal diseases, dysentery and to treat toothache in different regions of the country.

Objective: The study was designed to evaluate in vitro antibacterial activity of the crude stem bark extracts of S.kunthianum based on the result obtained from phytochemical exploration test.

Methods: The plant part was collected from Wayu Tuka district, and air dried. The powdered plant material was subjected to gradient extraction with solvent system using maceration technique and the constituent matter was concentrated, separated and collected for further investigation. Preliminary phytochemical screening test was made using the dried extract.

Results: Qualitative phytochemical exploration results showed that, the presence of alkaloid, flavonoids, terpenoids, saponins, Phenolics and tannins. The crude extract of the respected solvent containing relatively many phytochemicals was subjected to in vitro antibacterial evaluation using disc diffusion method against clinically isolated bacterial strains. In this study a promising results were recorded at higher concentration (500 ppm) of methanol extract against gram positive bacteria S. progens and S. aurous with zone of inhibition of $23 \pm 1.46$ and $21 \pm 0.71$, respectively and against gram negative strain, E.coli with zone of inhibition of $20 \pm 1.63$ showing close comparable antibacterial result with the antibiotics used as standard.

Conclusion: in vitro antibacterial result of this study depicts that, antibacterial effect of methanol stem bark extracts of S.kunthianum was positively associated due to the presence tannins and phenolic phytochemicals.

\section{Introduction}

Many plant species have been harnessed by humans for purposes of livelihood and quite a good number are being used in traditional medicine because of the efficacy. Herbal antimicrobials discovery have long been a popular research practice in the world. Following this, chemical synthesis, is playing a major role in providing widespread use of antimicrobial drugs originally from medicinal plants through easing devastation of natural resources and threat of extinction due to overexploitation. The world is in a state of current situation, expansion as an industry revolution, due to the spread of desertification, humans are extremely vulnerable to antibiotic resistant pathogens (Figure 1). Antibiotic-resistant strains of bacteria can lead to longer hospitalizations, longer treatment regimens and increased side-effects from the use of multiple and more powerful medications. This places an enormous burden on healthcare systems, using significant human and economic resources [1]. It is believed that, the search for antimicrobials should be carried out quickly and widely, as they are worrying the world about the rapid outspread of infectious diseases commonly spread through the direct transfer of bacteria, viruses or other germs from one person to another and animal-to-human. Based on this, the belief of the researchers 
is that, the probing for natural products that can be a lead compound for modern drug discovery should continue from a variety of plant species and its parts, because many conventional/pharmaceutical drugs are derived directly from both nature and traditional remedies distributed around the world [2].

Natural products have been used as good sources of many modern drugs that have been used for treatment of several human diseases. Traditionally used medicinal plants produce a variety of compounds of known therapeutic properties; in fact, it is the chemical constituents in plants that yield the medicinal properties [4, 5]. Stereospermum kunthianum (known by local name Botoro at Bonaya kebele Wayu Tuka district East Wollega Zone, Ethiopia; is a deciduous shrub or tree, 3-15 m high, with a stem diameter of $25 \mathrm{~cm}$. It is found in the dry areas of deciduous forest, woodland, bush, rocky outcrops, termite mound and margins of evergreen forests [6].

Different parts of a plant widely used by traditional medical practitioners for the treatment of various human diseases. For example, the pods are chewed with salt to treat coughs, ulcer, leprosy, skin eruptions, venereal diseases, curing bronchitis, pneumonia, cough, rheumatic arthritis and dysentery. The twigs are chewed to clean teeth and to treat toothache and wound. The roots and leaves have been found useful in treating venereal diseases, respiratory ailments, gastritis, and as-Analgesic, anti-inflammatory and anthelmintic activity as well [6-9].

\section{Chemicals, Reagents And Methods}

\subsection{Chemicals and Reagents}

The chemicals and reagents that were used in this study includes, Analytical Reagent grade solvents, Petroleum ether, (Blulux Laboratories Pvt.Ltd, India), Ethyl Acetate 95 \% (Loba Chemie Pvt.Ltd., India), methanol 99 \% (Sisco Research laboratories Pvt.Ltd., India) chloroform (Blulux laboratories Pvt.Ltd., India), Potassium lodide (UniChem Chemical, India), lodine (Samir Tech-Chem Pvt. Ltd., India), Sodium hydroxide (Loba Chemie Laboratory Reagents, Fine Chemicals, India.), Hydrochloric acid (Loba Chemie Laboratory Reagents, Fine Chemicals), Sulphuric acid, Ferric chloride and Acetic acid (Loba Chemie Pvt. Ltd., India).

\subsection{Methods}

\subsubsection{Plant sample collection and Extraction}

The stem bark of $S$. kunthianum plant was collected from around Bonaya kebele, Wayu Tuka district, East Wollega Zone, Ethiopia and air dried. The herbarium specimen was identified by Dr.Tena Regasa at Biology Department, Wollega University, Ethiopia; where a voucher specimen was deposited for reference. Three solvents were used for polarity gradient extraction of stem bark of the S. kunthainum 
using conventional extraction technique, i.e. maceration, starting from petroleum ether, ethyl acetate, and methanol. About 350 grams of fine powder of stem bark of S.kunthainum was placed in $2000 \mathrm{~mL}$ conical flask and extracted with $1500 \mathrm{ml}$ of Petroleum ether for 48 hours while shaking. Following this solvent extraction supernatant was filtered with filter paper (Whatman no 1 filter paper,) into filtrate and marc. The filtrate was kept for concentration but the Marc was allowed to dry at room temperature and the process of extraction was repeated with Ethyl acetate and methanol in the same manner successively. Solvents were removed from the filtrate by rotary evaporator (rotovap) (Buchi R-210 Rotavapor System) under reduced pressure and crude extracts were collected separately and made to dry at room temperature and the dried masses were weighed and the percentage yield was calculated and stored in refrigerator below $4^{\circ} \mathrm{C}[10]$, until used for preliminary qualitative phytochemical analysis and microbial assay.

\subsubsection{Phytochemical exploration}

Phytochemical examinations were carried out for all the extracts as per the standard methods. The collected plant extracts were subjected to qualitative phytochemical analysis for identification of various classes of active chemical constituent's i.e. secondary metabolities such as alkaloids, Flavonoids, Phenolics, saponins, terpenoids, glycosides, steroids and Tannins according to the methods discussed in the literatures [11-14]. The test solution was prepared by dissolving $1 \mathrm{~g}$ of each of crude extract of petroleum ether, ethyl acetate, methanol in $50 \mathrm{~mL}$ of respective solvents.

Test for Alkaloid (Wagner Test): To $1 \mathrm{~mL}$ of each crude extract (petroleum ether, ethyl acetate and methanol), a few drops of Wagner reagent (lodine in potassium iodide) was added. Formation of reddish brown precipitate indicates the presence of alkaloids.

Test for Flavonoids (Alkaline Reagent Test): $2 \mathrm{~mL}$ of each crude extract was treated with $2 \mathrm{~mL}$ of $2 \%$ $\mathrm{NaOH}$ solution and a few drops of Diluted acid were added. A formation of yellow color indicates the presence of flavonoid.

Test for phenolics (Ferric chloride Test): $1 \mathrm{~mL}$ of each crude extract was treated with 4 drops $5 \%$ ferric chloride. The appearance of bluish black color showed the presence of phenols.

Test for Terpenoids (Salkowski Test): $2 \mathrm{~mL}$ of stock solution of each crude extracts was treated with $2 \mathrm{~mL}$ of chloroform .Then $3 \mathrm{~mL}$ of concentrated Sulphuric acid was added. Golden yellow color indicates the presence of terpenoids.

Test for Saponins: $2 \mathrm{ml}$ of stock solution of each crude extract in a test tube, $2 \mathrm{~mL}$ of distilled water was added and vigorously shaken for 15 minutes. Formation of $1 \mathrm{~cm}$ foam confirms the presence of saponins.

Test for tannins: About $0.5 \mathrm{~g}$ each portion was stirred with about $10 \mathrm{ml}$ of distilled water and then filtered. Few drops of $1 \%$ ferric chloride solution were added to $2 \mathrm{ml}$ of the filtrate occurrence of a blue-black, green or blue-green precipitate indicates the presence of tannins. 
Test for steroids (Salkowski Test): To $2 \mathrm{~mL}$ of stock solution of each crude extract was added to $2 \mathrm{~mL}$ of chloroform followed by $3 \mathrm{~mL}$ concentrated sulphuric acid. Formation of red color showed the presence of steroids.

Test for glycosides (Liebermann's Test): $1 \mathrm{~mL}$ of stock solution each crude extract was mixed $2 \mathrm{~mL}$ of acetic acid and $2 \mathrm{~mL}$ of chloroform. The mixture was then cooled and a few drops concentrated $\mathrm{H}_{2} \mathrm{SO}_{4}$ was added. The presence of green color indicates the presence of glycosides.

\subsubsection{Microorganisms and Antibacterial Test:}

Test microorganisms were: Staphylococcus aureus, Streptococcus pyogenes, Escherichia coli and Klebsiella pneumoniae. All the organisms used in this study were clinical isolates obtained from Department of biology, College of Sciences, Bahir Dar University, Ethiopia.

Preparation of test solution for microbiological assay: $0.5 \mathrm{~g}$ of petroleum ether, ethyl acetate and methanol crude extracts were dissolved in $10 \mathrm{~mL}$ of DMSO to obtain a stock solution for antibacterial activity test.

Disc diffusion Methods: The three samples crude extracts, petroleum ether, ethylacetate and methanol were tested on the four test isolates. Standard antibiotic (Gentamycin) was adapted as positive control whereas, DMSO as negative control were assayed simultaneously. A series of plant extract concentrations $(50,100,200,300$, and 500$)$ ppm were added to clean and Sterilized discs with Mueller Hinton agar media seeded with selected gram negative and gram positive bacteria, incubated at $37^{\circ} \mathrm{C}$ for $24 \mathrm{hrs}$ to evaluate growth inhibition. The experiment was done triplicate, and average values of zone of inhibition was recorded in $\mathrm{mm}$ for its antibacterial activity test result verification.

\section{Results And Discussions}

\subsection{Determination of extraction yield}

Extraction yield was calculated according to the equation: \% Yield $=$ weight of the dry extract $x 100 /$ Total weight of powdered the dry plant material used [15] and the result is given in Table 1.

The amounts of percentage yields of plant extraction are look dependent on the solvent polarity used in the extraction. In agreement with this, methanol extract gave the largest mass of phytochemicals compared to that of petroleum ether and ethyl acetate extracts. This may be due to the highest polarity index of methanol [16] as compared to other solvents used. Accordingly, the results revealed that, to get a lot of secondary metabolites from the plant, it is necessary to use more polar solvents.

Table 1. Percent yield of petroleum ether, ethyl acetate and methanol extract of stem bark of $S$. kunthainum 


\begin{tabular}{|llll|}
\hline Plant and solvent extract & Dry powder $(\mathrm{g})$ & Yield (g) & Yield (g) \\
\hline Petroleum ether & 350 & 2.8 & 0.8 \\
\hline Ethyl acetate & 350.87 & 4 & 1.14 \\
\hline Methanol & 339.51 & 11 & 3.24 \\
\hline
\end{tabular}

\subsection{Phytochemicals screening result}

Phytochemical exploration of the crude extracts of the stem bark of S.kunthianum showed the presence of alkaloids, Flavonoids, Terpenoides saponins, Phenolics and tannins. While methanol extract gave a positive test for all phytochemicals tested including the others have. petroleum ether and ethyl acetate extracts showed the absence of Phenolics and tannin secondary metabolites tested in the stem bark of S.kunthianum (Scheme 1).

In Medicinal plants, complex chemical substances of different compositions are found as secondary plant metabolites in one or more of different parts of these plants and is widely used by traditional medical practitioners for the treatment of various human diseases [17]. S. kunthianum, in Ethiopia, has been reported to be used traditionally for treating various human aillments. According to M. Giday et al, stem bark, root and root bark of $S$. kunthianum plant is used to treat Diarrhoea, snake bit, scorpion bits and wound [18]. The aqueous extract of $S$. kunthianum stem bark possesses anti-inflammatory activity which is probably related to the inhibition of prostaglandin synthesis [19]. The roots and leaves have been found useful in treating venereal diseases, respiratory ailments, gastritis, respiratory ailments, Analgesic and anti-inflammatory, as well as the anthelmintic activity [20]. Kothai Seshathri reported that, Stereospermum kunthianum plant has Antimicrobial properties of Ethiopian chewing sticks against Candida albicans [21].

\subsection{Antibacterial activity result}

Here by the discussion of antibacterial activity result is based on the results obtained from phytochemical exploration (Scheme 1). The in vitro antibacterial test of methanol extracts of stem bark of S.kunthianum presented in Table 2, showed the susceptibility test against gram positive and gram negative organisms. The methanol extract exhibited close comparable level of inhibition against gram positive organisms compared to standard antibiotic gentamycin at $500 \mathrm{ppm}$. This is suggestive of the presence of some compounds or groups in the extracts with chemical functional group similar mechanism of action to that of gentamycin at higher concentrations. The highest activity was exhibited by crude extract against Streptococcus pyrogens $(23 \pm 1.46 \mathrm{~mm})$ and the lowest activity was exhibited against Klebsiella pneumonia ( $11 \pm 0.82 \mathrm{~mm}$ ) Table 2 . However, it was suggested that plant extracts exhibiting diameters of zones of inhibition exceeds $10 \mathrm{~mm}$ were considered to be active $[22,23]$.The result can therefore be considered as promising findings that, serve as a source of information about the plant type that, the researchers to do more work to find Antibiotics for antibiotic resistant pathogens. 
Table 2. Antibacterial inhibition zone of methanol stem bark crude extracts of S.kunthainum.

\begin{tabular}{|lllllllll|}
\hline \multirow{2}{*}{ Concentration of extracts $(\mathbf{p p m})$} & \multicolumn{3}{l}{ Zone of inhibition $(\mathrm{mm})$} \\
\cline { 2 - 9 } & \multicolumn{2}{l}{ Gram positive bacteria } & \multicolumn{2}{ll}{ Gram negative bacteria } \\
\cline { 2 - 9 } & S. aurous & S. pyrogens & E. coli & K. Pneumonia \\
\hline 50 & 12 & 0.65 & 19 & 0.19 & 15 & 0.20 & 8 & 0.28 \\
\hline 100 & 13 & 0.81 & 19 & 0.05 & 15 & 0.53 & 9 & 0.20 \\
\hline 200 & 13 & 0.43 & 20 & 0.57 & 15 & 0.41 & 10 & 0.48 \\
\hline 300 & 16 & 0.46 & 21 & 0.52 & 18 & 0.81 & 10 & 0.21 \\
\hline 500 & 21 & 0.71 & 23 & 1.46 & 20 & 1.63 & 11 & 0.82 \\
\hline
\end{tabular}

Key: data was expressed as a mean of three determinations ( ) standard deviation; $\mathrm{S}$. aurous = Staphylococcus aurous, $\mathrm{S}$. pyrogens $=$ Streptococcus pyrogens, $\mathrm{E}$. coli $=$ Escherichia coli, $\mathrm{K}$ pneumonia $=$ Klebsiella pneumonia.

The methanol extract under study have shown considerable antibacterial effect; therefore, thus this can be attributed to primarily the presence of tannins and phenolics (Schem 1). Tannins have been reported to inhibit growth of microorganisms by precipitating microbial protein and making nutritional protein unavailable to them $[24,25]$. Either way or in contrast, the flavonoids have been known to be synthesized by plants in response to microbial infection, while Saponins also have been reported to exhibit wide range of biological activities especially antibacterial whose mode of action involves cell membrane lysis [26]. The presence of phenolic hydroxyl groups (Section 2.3) with high protein binding affinity may inhibit microbial enzymes and simultaneously increase affinity to cytoplasmic membranes, consequently enhancing the antibacterial activity [27]; thus the high activities exhibited by the methanol soluble portion could be as a results of it containing most of the secondary metabolites found in the extracts.

\section{Conclusions}

The observed antibacterial activity of methanol stem barks extracts of S.kunthainum justify the traditional use of the plant for the treatment of different bacterial infections. In addition, though, there are compounds reported with annotated structures from the plant, the researches try to recommend that, purification of the active extracts and elucidation of the structures with relative stereochemistries from the plant should be carried out in wide, that can be lead compounds in pharmaceutical industry for modern drug to manage antibiotic resistant bacterial infections.

\section{Declarations}




\section{Ethics approval and consent to participate}

Not applicable" in this section.

\section{Consent for publication}

Not applicable" in this section.

\section{Availability of data and materials}

Data sharing not applicable to this article as no datasets were generated or analyzed during the current study. If you do not wish to publicly share your data, please write: "Please contact author for data requests.

\section{Competing interests}

The authors declare that they have no competing interests. If you are unsure whether you or any of your co-authors have a competing interest please contact the editorial office.

\section{Funding}

Designing of the study, data collection and analysis, interpretation of data and writing of the manuscript was financially supported by Department of Chemistry, Institute of post graduate studies, Bahir Dar University, Ethiopia

\section{Authors' contributions}

i. Ameja LB. designs the study title and prepared the study figures.

ii. Kassa MT. performed phytochemical exploration, and was a major contributor in writing the manuscript.

iii. Bahiru LA. Carried out antibacterial activity studies, participated in the sequence alignment and drafting the manuscript.

iv. Ayana MT. Carried out in vitro antibacterial evaluation helped to draft the manuscript.

v. Derese ZB. Participated in the experimental sequence alignment.

vi. Yihun FA. participated in the design of the study and performed the tabulation of the experimental result

vii. Tariku Y. participated in designing schematic representation and helped to draft the manuscript. viii. All authors read and approved the final manuscript.

\section{Acknowledgements}

Not applicable" in this section. 


\section{References}

1. Bengtsson, B. and C. Greko, Antibiotic resistance-consequences for animal health, welfare, and food production. Upsala journal of medical sciences, 2014. 119(2): p. 96-102.

2. Pan, S.Y., et al., Historical perspective of traditional indigenous medical practices: the current renaissance and conservation of herbal resources. Evid Based Complement Alternat Med, 2014. 2014: p. 525340.

3. Wilson, M., Home» Global Health» World Antibiotic Awareness Week-what are the reasons for and implications of antibiotic resistance? Part 2.

4. Yuan, $\mathrm{H}$., et al., The traditional medicine and modern medicine from natural products. Molecules, 2016. 21(5): p. 559.

5. Tesemma, M., et al., Isolation of compounds from acetone extract of root wood of Moringa stenopetala and evaluation of their antibacterial activities. Research Journal of Medicinal Plant, 2013. 7(1): p. 32-47.

6. Ching, F. and E. Omogbai, Effects of sub acute oral administration of aqueous extract of Stereospermum kunthianum (Bignoniaceae) stem bark on body weight and haematological indices of rats. Journal of Pharmacy \& Bioresources, 2010. 7(2): p. 127-131.

7. Sarr, A., et al., Phytochemical Screening and Determination of Polyphenols in the Hydro-Ethanolic Extract of Trunk Bark and Its Fractions of Stereospermum kunthianium Cham (Bignoniaceae). Asian Plant Research Journal, 2021: p. 1-9.

8. Tsala, D.E., et al., In vivo wound healing effect of water extract of stereospernum kunthianum stembark. Journal of medicinal herbs and ethnomedicine, 2016. 2: p. 1-6.

9. Ching, F., et al., Antidiarrhoeal activities of aqueous extract of Stereospermum kunthianum (Cham, Sandrine Petit) stem bark in rodents. African Journal of Biotechnology, 2008. 7(9).

10. Antonio, M., A. Ricardo, and G. Walter, In Vitro Antiplasmodial Investigation Of Medicinal Plants From El Salvador ÂA $\S$. Zeitschrift f $\tilde{A} 1 / 4$ r Naturforschung C, 2014.

11. Pandey, A. and S. Tripathi, Concept of standardization, extraction and pre phytochemical screening strategies for herbal drug. Journal of Pharmacognosy and Phytochemistry, 2014. 2(5).

12. Mulata, H., et al., Phytochemical screening and assessment of in vitro antioxidant activities of Calpurnia aurea seeds and leaves. ljppr Human, 2015. 2(2): p. 1-12.

13. Gul, R., et al., Preliminary phytochemical screening, quantitative analysis of alkaloids, and antioxidant activity of crude plant extracts from Ephedra intermedia indigenous to Balochistan. The Scientific World Journal, 2017. 2017.

14. Debiyi, O. and F. Sofowora, Pytochemical screening of medical plants. Iloyidia, 1978. 3: p. 234-246.

15. Nkafamiya, I., et al., Percentage oil yield and physiochemical properties of different groundnut species (Arachis hypogaea). African Journal of Food Science, 2010. 4(7): p. 418-421.

16. Gupta, M.N., et al., Polarity index: the guiding solvent parameter for enzyme stability in aqueousorganic cosolvent mixtures. Biotechnology progress, 1997. 13(3): p. 284-288. 
17. Aliyu, M., et al., Phytochemical and antibacterial properties of leaf extract of Stereospermum kunthianum (Bignoniaceae). Nigerian Journal of Basic and Applied Sciences, 2009. 17(2): p. 235239.

18. Giday, M., et al., Medicinal plants of the Shinasha, Agew-awi and Amhara peoples in northwest Ethiopia. Journal of Ethnopharmacology, 2007. 110(3): p. 516-525.

19. Omogbai, E., et al., Analgesic activities of fractions of Stereospermum kunthianum stem bark. The Internet Journal of Pharmacology, 2010. 8(1): p. 2010.

20. Ching, F.P., et al., Analgesic activity of aqueous extract of Stereospermum kunthianum (Cham, Sandrine Petit) stem bark. Acta Poloniae Pharmaceutica-Drug Research, 2009. 66(1): p. 83-88.

21. Seshathri, K., Antimicrobial properties of Ethiopian chewing sticks against Candida albicans. Journal of Applied Pharmaceutical Science, 2012. 2(2): p. 45.

22. Usman, H. and J.C. Osuji, Phytochemical and in vitro antimicrobial assay of the leaf extract of Newbouldia laevis. African Journal of Traditional, Complementary and Alternative Medicines, 2007. 4(4): p. 476-480.

23. Nwinyi, O.C., S. Chinedu, and O.O. Ajani, Evaluation of antibacterial activity of Pisidium guajava and Gongronema latifolium. Journal of Medicinal Plants Research, 2008. 2(8): p. 189-192.

24. Funatogawa, K., et al., Antibacterial activity of hydrolyzable tannins derived from medicinal plants against Helicobacter pylori. Microbiology and immunology, 2004. 48(4): p. 251-261.

25. Usman, H., et al., Phytochemical and in-vitro antibacterial effects of the partitioned portions of Bauhinia rufescens Lam stem bark extract. African Journal of Biomedical Research, 2009. 12(3): p. 210-218.

26. Al-Bayati, F.A. and H.F. Al-Mola, Antibacterial and antifungal activities of different parts of Tribulus terrestris L. growing in Iraq. J Zhejiang Univ Sci B, 2008. 9(2): p. 154-9.

27. Maddox, C.E., L.M. Laur, and L. Tian, Antibacterial activity of phenolic compounds against the phytopathogen Xylella fastidiosa. Curr Microbiol, 2010. 60(1): p. 53-8.

\section{Scheme}

Scheme 1 is available in Supplemental Files section.

\section{Figures}




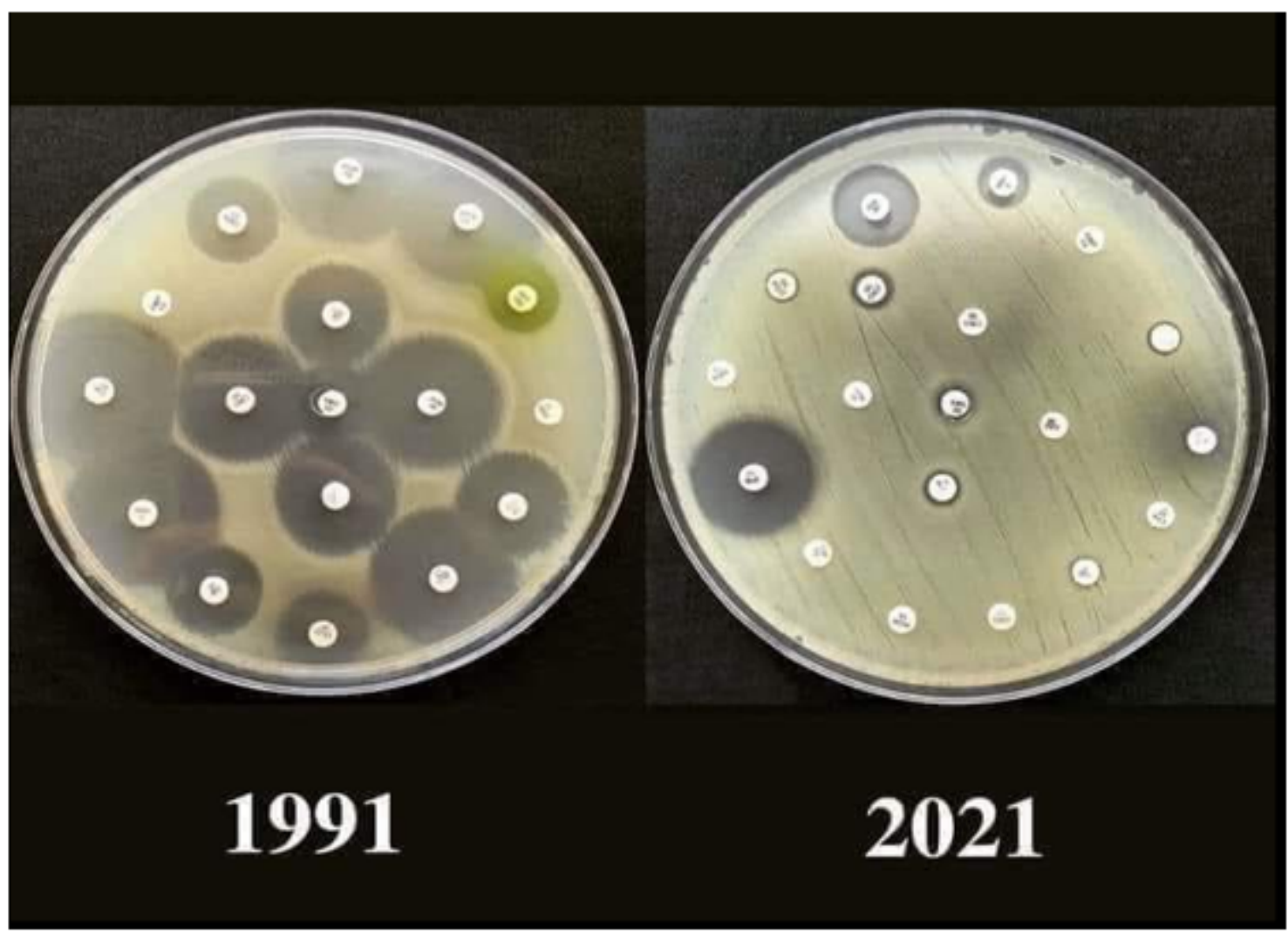

Figure 1

The picture taken from World antibiotic awareness week 2021 as heartbreaking homework for a Microbiologist [3] 


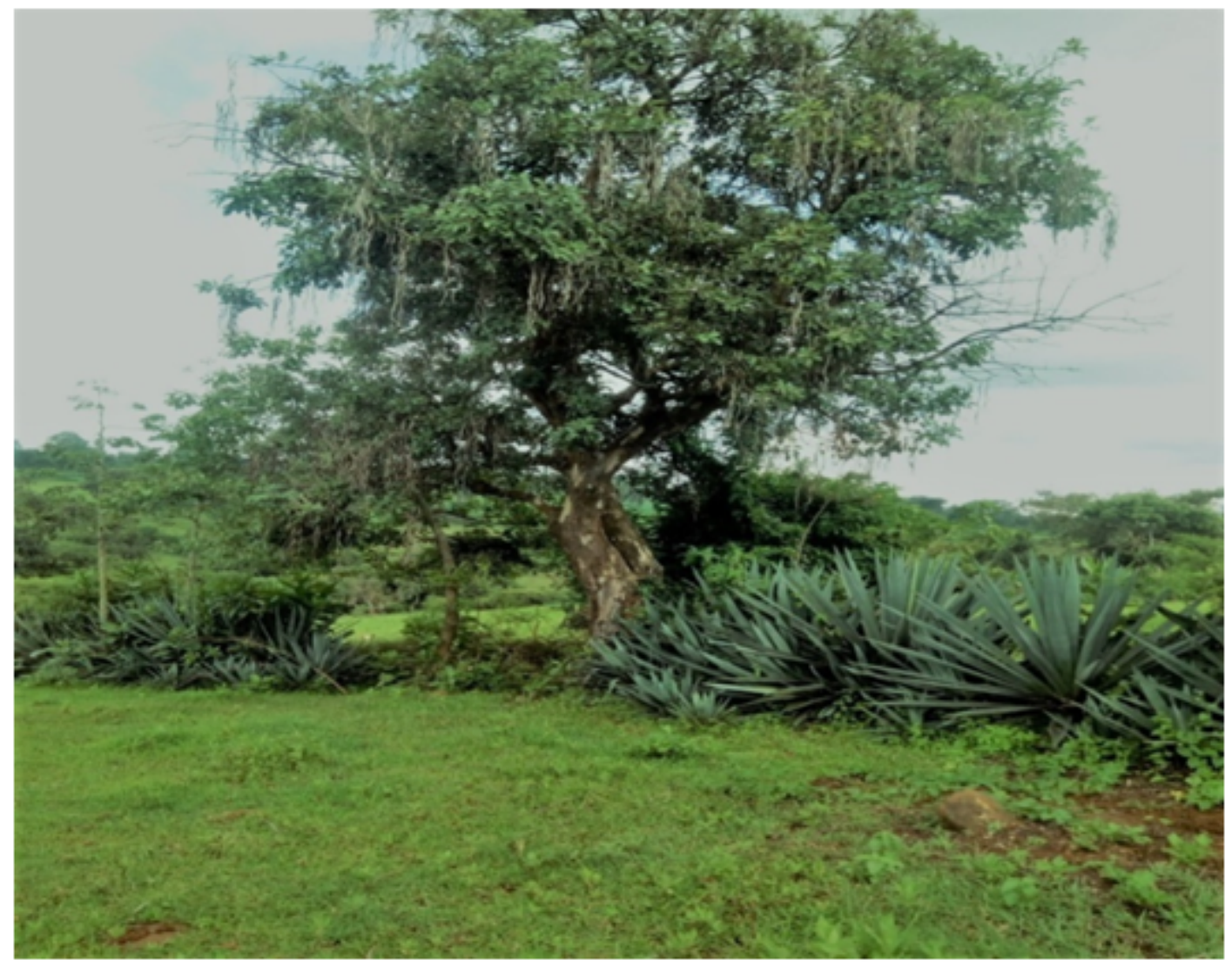

Figure 2

Stereospermum kunthianumplant (known by local name Botoro) at Wayu Tuka district East Wollega Zone, Ethiopia (Picture taken by Lamessa Bekele in May, 2021).

\section{Supplementary Files}

This is a list of supplementary files associated with this preprint. Click to download.

- scheme1.png 